\title{
Buccally Malposed Maxillary Canines in Intermediate Schools Students of Sammawa City
}

Hayder Saad Al-Atabi

B.D.S., M.Sc. - Lecturer. Department of POP. College of Dentistry, University of Al-Muthanna.

Hara'a S. Mohammed-Salih

B.D.S., M.Sc. - Lecturer. Department of Orthodontics. College of Dentistry, University of Baghdad.

Mohammed Nahidh

B.D.S., M.Sc. - Assistant Professor. Department of Orthodontics. College of Dentistry, University of Baghdad.

\begin{abstract}
Background: Canines are unique teeth because they have certain characteristics and responsibilities. They are located in the corner of the mouth, assist the incisors in cutting and tearing food, help the posterior teeth by guiding the mandible during the action of mastication. This survey aimed to determine the prevalence and gender difference of buccally malposed maxillary canines and to study the relation of this problem with the sagittal occlusion, crowding, retard deciduous canine and lack of space in the dental arch in a sample of intermediate schools students from Sammawa city.

Materials and methods: A total of 3200 students (1600 males and 1600 females) aged 13-14 years old from Sammawa city were examined to detect the buccally malposed maxillary canines. For each diagnosed case, the sagittal occlusion, the sides affected on the maxillary arch, angulation of the canines, presence of crowding, retard deciduous canine and space lacking were determined. Z-score test was used to detect the gender difference, while Chi square test was applied to correlate the canine malposition with other factors.

Results : In general 311(9.72\%) of total sample have buccally malposed maxillary canines. Of them, 163(10.19\%) were males and $148(9.25 \%)$ were females. This problem appeared to be higher in class I than other sagittal relations. Mesially angulated canine was more prevalent than distally one and in right more than left with non-significant gender difference. The prevalence of buccally malposed maxillary canines with the presence of crowding and retard primary canines was higher in males than females with non-significant gender difference. There was high significant association between buccally malposed canine and lacking of space. Conclusions: Regular visits of the children to the general practitioners and /or orthodontists are mandatory trying to preserve the deciduous teeth and to educate the parents about the importance of these teeth. In addition to that, the age between 9 to 10 years is important to detect the bulging of canines trying to minimize the possibility of ectopic canine eruption.
\end{abstract}

KEY WORDS

Prevalence, canines, Sammawa city.

CITE THIS ARTCLE

Al-Atabi H, Mohammed-Salih H, Nahidh M. Buccally Malposed Maxillary Canines in Intermediate Schools Students of Sammawa City. Iraqi Dent. J. 2016; 38(1):21-27. http://www.iraqidentaljournal.com

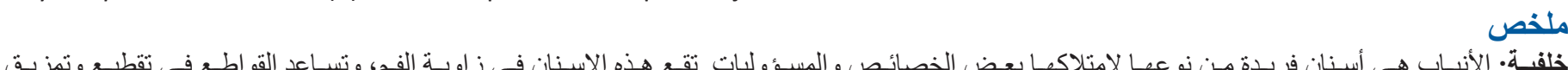

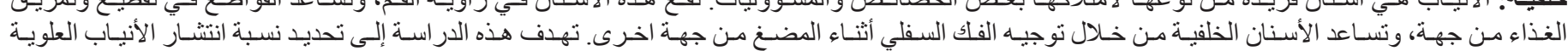

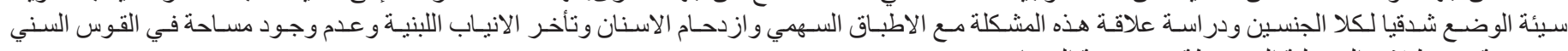

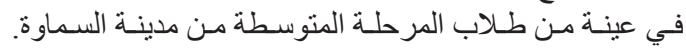

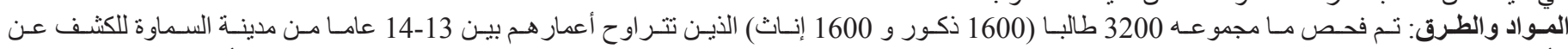

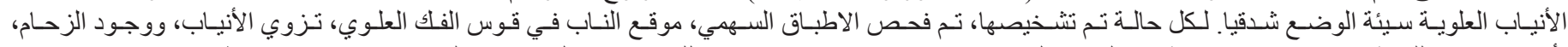

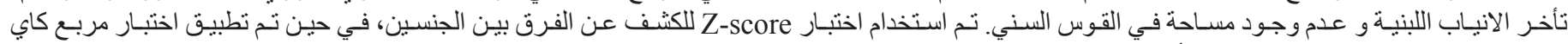

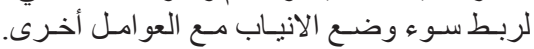

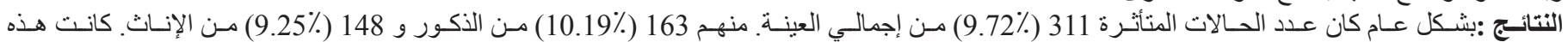

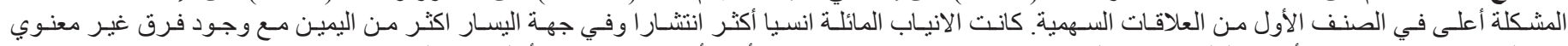

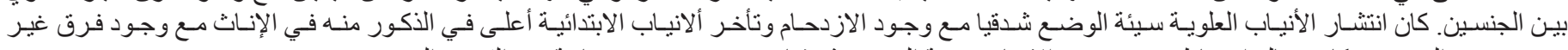

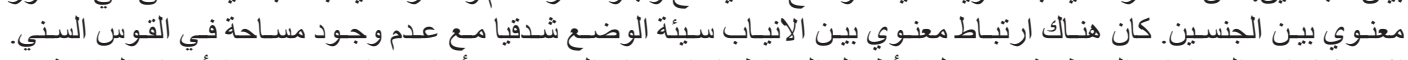

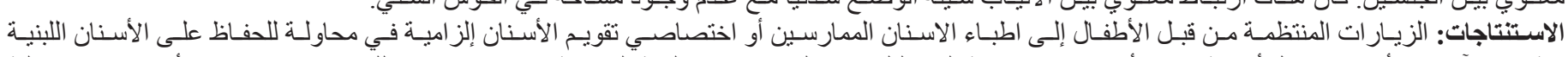

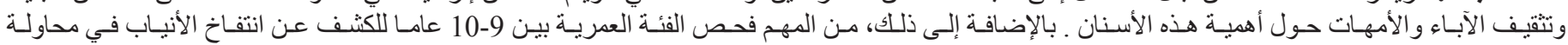

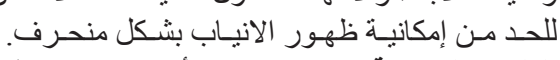

\section{INTRODUCTION}

Human beings have four pointed teeth one on each side of the dental arch called canine or cuspid. Each canine represents the third tooth from the median line after the central and lateral incisors forming the key stone or the corner stone of the dental $\operatorname{arch}^{(1)}$.

The maxillary canines possess crowns that are as long as the crowns of the central incisors with single root longer than that of any tooth. The shape and position of the canines contributed to the guidance of the teeth into the inter-cuspal position by "canine guidance." (2)

Several characteristics of the functional form of canine crowns had a clear similarity to that of incisor and premolar. Due to possessing crowns with single pointed cusps and long roots in addition to their location in the corner of the mouth, canines resemble the prehensile teeth of the carnivore, hence the name 
come. Generally, the labio-lingual thickness of the crown and the root of the canine and its anchorage in the alveolar process make this tooth the most stable one in the mouth. The shape of the crown promotes the self-cleaning property, so it is the last tooth to be lost.

The bony ridge over the labial portion of the canine's root in addition to the form and position of the canine give it more cosmetic importance ${ }^{(3)}$.

Due to these characteristics, it plays a great role in keeping up the contour and shape of the dental arch, occlusion and facial expression, in addition to its role in mastication, appearance and prosthetic treatment (4).

From developmental point of view, Dewel (5) stressed on the maxillary canine as it had the longest period of development from the deepest area (below the orbit) and it had the most tortuous path of eruption from the point of origin till full occlusion. These factors made maxillary canines more susceptible to favorable or unfavorable environmental influences.

The calcification process of maxillary permanent canine crown begins at 4 months of age and completed at 6-7 years of age. It erupts in the oral cavity at 11-12 years old and its roots completed at 13-15 years old (6)

Sachan and Chaturvedi (7) summarized the etiological factors of ectopic canines as followed:

1.Early loss of deciduous teeth

2.Crowding of the permanent successor

3.Tooth size and overall arch length

4.High developmental position and long path of eruption and tortuous movement

5.Prolonged retention of the deciduous tooth

6.Failure of primary canine root resorption

7.Small or congenital missing permanent lateral incisor

8.Reduced in the length of the adjacent lateral incisor root

9.Ankylosis of permanent canine

10.Alveolar cleft

11.Malposed tooth germ

12.Hereditary factors

13.Endocrine deficiency

14.Febrile diseases.

Many studies ${ }^{(8-22)}$ have been conducted in Iraq to study the problems of canines. Some of them concern with canine specifically and the other took the maxillary canine as a part from the survey.

This survey was conducted to study the prevalence of buccally malposed maxillary canines in Sammawa city and to find out the gender and sides' difference of this type of malocclusion in addition to the relation with the presence of crowding, retard deciduous canine and lacking of space.

\section{MATERIALS AND METHODS Sample}

This study was conducted from 5 October 2014 to 29 April 2015 on a sample consisted of 3200 students (1600 males and 1600 females) attending intermediate schools in Sammawa city ( $280 \mathrm{~km}$ to the south of Baghdad).

Age was considered according to the last birthday giving an age range from 13 years 0 months to 14 years 11 months ${ }^{(23)}$.

Permission was acquired from the Al-Muthanna directorate of education. The schools' authorities were contacted and the purpose of the study was explained to them to ensure full cooperation.

\section{Criteria of the sample selection}

1.All subjects are Iraqis Arabs in origin.

2.No history of orthodontic treatment.

3.Any gross facial asymmetry was excluded

4.No history of systemic disease or regular drug used for chronic disease that affecting the growth of the body.

5.Cases of cleft lip and palate were excluded.

\section{Methods}

The following instruments and equipment were used: disposable dental mirrors, kidney dish, millimeter graded vernier (INOX, Zurcher Modell, Asset plant and machinery Pty. Ltd., China), plastic ruler with $15^{\circ}$ angle cut, medical cotton, medical gloves, cheek retractor, disinfected solution (Desident Cavicide, Spofadental, Czech), portable torch light and case sheet to register the information obtained.

The examination was carried out in rooms that were available in host school. The subjects were seated on ordinary chairs with their heads supported in an upright position and the examiner stood in front of the chair to get direct view of both sides of the mouth ${ }^{(24)}$ and determined the following parameters:

\section{Angulation of the buccally malposed maxillary canines}

Mesial or distal tipping or angulation of fully erupted permanent maxillary canine was recorded when it exceeded $15^{\circ}$ using modified plastic ruler ${ }^{(25)}$.

\section{Sagittal occlusion}

Depending on Angle's classification (26), the sagittal occlusion was determined by examining the 
$1^{\text {st }}$ permanent molar relationship:

a.Normal molar occlusion (class I): It is registered when the mesio-buccal cusp of the upper first permanent molar occludes with the anterior buccal groove of the lower first permanent molar.

b.Distal molar occlusion (class II): It is observed when the relative position of mandibular molar has shifted distally by half cusp width or more.

c.Mesial molar occlusion (class III): The relative position of the mandibular molar had shifted mesially by half a cusp width or more.

\section{Presence of crowding}

The dental arch was divided into three segments; one incisal and two lateral segments (right and left). The incisal segment was demarcated by the distal contact points of the two lateral incisors, while the lateral segments were limited by these points and the mesial contact points of the first molars ${ }^{(25)}$.

Crowding (a shortage of $2 \mathrm{~mm}$ or more of space preventing the correct alignment of all teeth in that segment) was recorded for each segment with the aid of vernier ${ }^{(24)}$.

\section{Presence of retard deciduous tooth}

Retard deciduous tooth (a tooth remained in the mouth beyond its normal time of shedding) was denoted as persistent when, owing to aplasia or anomalous eruption of the equivalent permanent teeth ${ }^{(25)}$.

\section{Lack of space}

Present due to premature extraction of primary teeth causing mesial shifting of the permanent teeth and block the space of canine.

\section{Statistical Analysis}

The data were processed and analyzed by using SPSS program version 21. The statistical analyses included descriptive statistics (frequency and percentages) and inferential statistics ( $Z$ score test for comparison between both genders and Chi square test to detect the association between the determined parameters and malposed canines).

The following levels of significance are used:

$\begin{array}{lll}\text { Non-significant } & \text { NS } & \mathrm{P}>0.05 \\ \text { Significant } & \mathrm{S} & 0.05 \geq \mathrm{P}>0.01 \\ \text { Highly significant } & \text { HS } & \mathrm{P} \leq 0.01\end{array}$

\section{RESULTS}

\section{Prevalence of the buccally malposed maxillary canines according to genders}

The total sample consisted of 3200 students (1600 males and 1600 females). From this total sample, only $311(9.72 \%)$ were found to have buccally malposed maxillary canine, of them 163(10.19\%) males and 148(9.25\%) females (Table 1).

Table 1: Distribution of buccally malposed maxillary canines according to genders

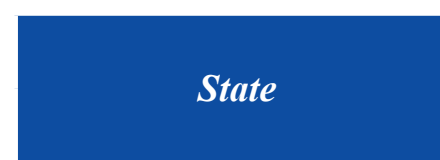

\begin{tabular}{c|}
\hline Affected \\
\hline Not affected \\
\hline Total \\
\hline
\end{tabular}

\begin{tabular}{|c|c|}
\hline \multicolumn{2}{|c|}{ Total } \\
\hline No. & $\%$ \\
\hline 311 & 9.72 \\
\hline 2889 & 90.28 \\
\hline 3200 & 100 \\
\hline
\end{tabular}

3200

\begin{tabular}{|c|c|}
\hline \multicolumn{2}{|c|}{ Males } \\
\hline No. & $\%$ \\
\hline 163 & 10.19 \\
\hline 1437 & 89.81 \\
\hline 1600 & 100 \\
\hline
\end{tabular}

\begin{tabular}{|c|c|}
\hline \multicolumn{2}{|c|}{ Females } \\
\hline No. & $\%$ \\
\hline 148 & 9.25 \\
\hline 1452 & 90.75 \\
\hline 1600 & 100 \\
\hline
\end{tabular}

Distribution of the buccally malposed maxillary canines according to the side of the problem

As shown in table 2, unilateral buccally malposed

canine was more prevalent than bilateral malposition and in males more than females with a non-significant gender difference.

Table 2: Distribution of the buccally malposed maxillary canines according to state of malocclusion in both genders

\begin{tabular}{c|c|c|c|c|c|c|c|c|c|}
\hline \multirow{2}{*}{$\begin{array}{c}\text { State of } \\
\text { malposition }\end{array}$} & \multicolumn{2}{|c|}{ Total } & \multicolumn{2}{c|}{ Males } & \multicolumn{2}{c|}{ Females } & \multicolumn{2}{c|}{ Gender difference } \\
\cline { 2 - 9 } & No. & $\%$ & No. & $\%$ & No. & $\%$ & Z-test \\
\hline Unilateral & 211 & 67.85 & 110 & 67.48 & 101 & 68.24 & -0.143 & 0.889 (NS) \\
\hline Bilateral & 100 & 32.15 & 53 & 32.52 & 47 & 31.76 & 0.143 & 0.889 (NS) \\
\hline Total & 311 & 100 & 163 & 100 & 148 & 100 & \\
\hline
\end{tabular}


Buccally malposed maxillary canines showed in 100 cases; 53 in males and 47 in female with a high frequency in the right side than the left with a non-significant gender difference. The association non-significant gender difference (Table 3). Buccal between the side of canine malposition and genders maxillary canine malposition on both side appeared was non-significant.

Table 3: Distribution of buccally malposed maxillary canines according to the sides' maxillary arch

\begin{tabular}{|c|c|c|c|c|c|c|c|c|}
\hline \multirow{2}{*}{$\begin{array}{c}\text { Side of } \\
\text { problem }\end{array}$} & \multicolumn{2}{|c|}{ Total } & \multicolumn{2}{|c|}{ Males } & \multicolumn{2}{c|}{ Females } & \multicolumn{2}{c|}{ Genders difference } \\
\cline { 2 - 10 } & No. & $\%$ & No. & $\%$ & No. & $\%$ & Z-test & p-value \\
\hline Right side & 133 & 42.77 & 68 & 41.72 & 65 & 43.92 & -0.392 & 0.697 (NS) \\
\hline Left side & 78 & 25.08 & 42 & 25.77 & 36 & 24.32 & 0.293 & $0.772(\mathrm{NS})$ \\
\hline Both sides & 100 & 32.15 & 53 & 32.52 & 47 & 31.76 & 0.143 & 0.889 (NS) \\
\hline Total & 311 & 100 & 163 & 100 & 148 & 100 & & \\
\hline
\end{tabular}

$X^{2}=0.166$, d.f. $=2$, p-value $=0.920$ (NS)

Buccally malposed maxillary canines in relation to presented in class I cases followed by class II and the sagittal occlusion

Distribution of buccally malposed maxillary canines in relation to sagittal occlusion in both genders was demonstrated in table 4.

the least in class III. Z-test revealed non-significant gender difference. Chi-square test disclosed nonsignificant association between the sagittal occlusal relation and genders.

Generally the highest number of cases was

Table 4: Distribution of buccally malposed maxillary canine in relation to sagittal occlusion

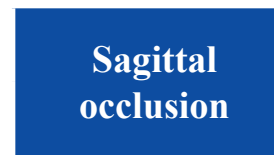

\begin{tabular}{|c|}
\hline Class I \\
\hline Class II \\
\hline Class III \\
\hline Total \\
\hline
\end{tabular}

\begin{tabular}{|c|}
\hline No. \\
\hline 222 \\
\hline 63 \\
\hline 26 \\
\hline 311 \\
\hline
\end{tabular}

\begin{tabular}{|c|c|}
\hline \multicolumn{2}{|c|}{ Males } \\
\hline No. & $\%$ \\
\hline 113 & 69.32 \\
\hline 37 & 22.70 \\
\hline 13 & 7.98 \\
\hline 163 & 100 \\
\hline
\end{tabular}

\begin{tabular}{|c|c|}
\hline \multicolumn{2}{|c|}{ Females } \\
\hline No. & $\%$ \\
\hline 109 & 73.65 \\
\hline 26 & 17.57 \\
\hline 13 & 8.78 \\
\hline 148 & 100 \\
\hline
\end{tabular}

\begin{tabular}{|c|c|}
\hline \multicolumn{2}{|c|}{ Genders difference } \\
\hline Z-test & p-value \\
\hline-0.843 & $0.401(\mathrm{NS})$ \\
\hline 1.125 & $0.263(\mathrm{NS})$ \\
\hline-0.257 & $\mathbf{0 . 7 9 5}(\mathrm{NS})$ \\
\hline
\end{tabular}

$X^{2}=1.272$, d.f. $=2, p$-value $=0.529$ (NS)

Angulations of buccally malposed maxillary distally. Generally, both of the types of angulations canines

Table 5 demonstrated distribution of the buccally malposed maxillary canine according to its angulation. Mesially angulated maxillary canine was presented in 281 cases while in 30 cases, the canine angulated were higher in the right side that of the left. Chisquare tests revealed a non-significant association between the angulation of canine malposition and the side of occurrence in the maxillary arch.

Table 5: Distribution of buccally malposed maxillary canines according to its angulation on the sides of maxillary arch

\begin{tabular}{|c|}
\hline Side of \\
problem
\end{tabular}

\begin{tabular}{|c|c|}
\hline \multicolumn{2}{|c|}{ Total } \\
\hline No. & $\%$ \\
\hline 133 & 42.77 \\
\hline 78 & 25.08 \\
\hline 100 & 32.15 \\
\hline 311 & 100 \\
\hline
\end{tabular}

\begin{tabular}{|c|c|}
\hline \multicolumn{2}{|c|}{ Mesially } \\
\hline No. & $\%$ \\
\hline 121 & 43.06 \\
\hline 71 & 25.27 \\
\hline 89 & 31.67 \\
\hline 281 & 100 \\
\hline
\end{tabular}

\begin{tabular}{|c|c|}
\hline \multicolumn{2}{|c|}{ Distally } \\
\hline No. & $\%$ \\
\hline 12 & 40 \\
\hline 7 & 23.33 \\
\hline 11 & 36.67 \\
\hline 30 & 100 \\
\hline
\end{tabular}

$X^{2}=0.31$, d.f. $=2$, p-value $=0.856(\mathrm{NS})$

The frequency of mesially angulated buccally malposed canines were presented in males more than females in each side and in both side cases with a non-significant genders difference. Non-significant association was found between the genders and the side of malposition (Table 6). 
Table 6: Distribution of mesially angulated buccally malposed canine according to the sides' maxillary arch

\begin{tabular}{|c|c|c|c|c|c|c|c|c|}
\hline \multirow{2}{*}{$\begin{array}{c}\text { Side of } \\
\text { problem }\end{array}$} & \multicolumn{2}{|c|}{ Total } & \multicolumn{2}{|c|}{ Males } & \multicolumn{2}{c|}{ Females } & \multicolumn{2}{c|}{ Genders difference } \\
\cline { 2 - 10 } & No. & $\%$ & No. & $\%$ & No. & $\%$ & Z-test & p-value \\
\hline Right side & 121 & 43.06 & 62 & 42.18 & 59 & 44.03 & -0.313 & $0.757(\mathrm{NS})$ \\
\hline Left side & 71 & 25.27 & 38 & 25.85 & 33 & 24.63 & 0.236 & $0.810(\mathrm{NS})$ \\
\hline Both sides & 89 & 31.67 & 47 & 31.97 & 42 & 31.34 & 0.113 & $0.912(\mathrm{NS})$ \\
\hline Total & 281 & 100 & 147 & 100 & 134 & 100 & & \\
\hline
\end{tabular}

$X^{2}=0.106$, d.f. $=2$, p-value $=0.948(\mathrm{NS})$

The distally angulated buccally malposed canines in both sides with a non-significant gender difference. were presented in 16 males and 14 females with Again, no significant association was found between nearly equal distribution on each side of the arch and the gender and the side of the problem (Table 7).

Table 7: Distribution of distally angulated buccally malposed canine according to the sides' maxillary arch

\begin{tabular}{|c|c|c|c|c|c|c|c|c|}
\hline \multirow{2}{*}{ Side of problem } & \multicolumn{2}{|c|}{ Total } & \multicolumn{2}{|c|}{ Males } & \multicolumn{2}{c|}{ Females } & \multicolumn{2}{c|}{ Genders difference } \\
\cline { 2 - 11 } & No. & $\%$ & No. & $\%$ & No. & $\%$ & Z-test & p-value \\
\hline Right side & 12 & 40 & 6 & 37.5 & 6 & 42.86 & -0.299 & 0.764 (NS) \\
\hline Left side & 7 & 23.33 & 4 & 25 & 3 & 21.43 & 0.231 & 0.818 (NS) \\
\hline Both sides & 11 & 36.67 & 6 & 37.5 & 5 & 35.71 & 0.101 & $0.920(\mathrm{NS})$ \\
\hline Total & 30 & 100 & 16 & 100 & 14 & 100 & & \\
\hline
\end{tabular}

$X^{2}=0.101$, d.f. $=2$, p-value $=0.950$ (NS)

Buccally malposed maxillary canine in relation to appeared in 206 cases (107 cases in males and 99 crowding cases in females). There was non-significant gender

Table 8 showed the distribution of buccally difference in each side and in both side, also no malposed canines in relation to crowding on the sides significant association existed between the gender of the maxillary arch in both gender. The crowding and the side of crowding.

Table 8: Distribution of buccally malposed maxillary canines on sides of the maxillary arch associated with crowding

\begin{tabular}{|c|c|c|c|c|c|c|c|c|}
\hline \multirow{2}{*}{$\begin{array}{c}\text { Side of } \\
\text { problem }\end{array}$} & \multicolumn{2}{|c|}{ Total } & \multicolumn{2}{|c|}{ Males } & \multicolumn{2}{c|}{ Females } & \multicolumn{2}{c|}{ Genders difference } \\
\cline { 2 - 11 } & No. & $\%$ & No. & $\%$ & No. & $\%$ & Z-test & $p$-value \\
\hline Right side & 84 & 40.78 & 44 & 41.12 & 40 & 40.40 & 0.105 & 0.920 (NS) \\
\hline Left side & 55 & 26.70 & 29 & 27.10 & 26 & 26.26 & 0.136 & 0.889 (NS) \\
\hline Both sides & 67 & 32.52 & 34 & 31.78 & 33 & 33.33 & -0.238 & 0.810 (NS) \\
\hline Total & 206 & 100 & 107 & 100 & 99 & 100 & & \\
\hline
\end{tabular}

$X^{2}=0.058$, d.f. $=2$, p-value $=0.971(\mathrm{NS})$

Buccally malposed maxillary canine in relation to gender difference or association between the retard retard deciduous canine

The retard deciduous canine with buccally canine were recorded (Table 9). malposed canines were presented in 69 cases; 37 cases in males and 32 cases in females. No significant

Table 9: Distribution of buccally malposed maxillary canines on sides of the maxillary arch associated with retard deciduous canine

\begin{tabular}{|c|c|c|c|c|c|c|c|c|}
\hline \multirow{2}{*}{$\begin{array}{c}\text { Retard deciduous } \\
\text { canine }\end{array}$} & \multicolumn{2}{|c|}{ Total } & \multicolumn{2}{|c|}{ Males } & \multicolumn{2}{c|}{ Females } & \multicolumn{2}{c|}{ Genders difference } \\
\cline { 2 - 10 } & No. & $\%$ & No. & $\%$ & No. & $\%$ & Z-test & p-value \\
\hline Right side & 27 & 39.13 & 13 & 35.14 & 14 & 43.75 & -0.731 & $0.465(\mathrm{NS})$ \\
\hline Left side & 18 & 26.09 & 10 & 27.03 & 8 & 25 & 0.191 & $0.849(\mathrm{NS})$ \\
\hline Both sides & 24 & 34.78 & 14 & 37.84 & 10 & 31.25 & 0.573 & $0.567(\mathrm{NS})$ \\
\hline Total & 69 & 100 & 37 & 100 & 32 & 100 & & \\
\hline
\end{tabular}


Buccally malposed maxillary canine in relation to space lacking

The space lacking for buccally malposed canines were presented in 205 cases, 121 cases of them in males and 84 in females with a high significant gender difference in cases of both sides and non-significant gender difference in each side separately.

Chi-square test revealed a highly significant association between the lack of space and buccal canine malposition with regard to genders (Table 10).

Table 10: Distribution of buccally malposed maxillary canines on sides of the maxillary arch associated with lack of space

\begin{tabular}{|c|c|c|c|c|c|c|c|c|}
\hline \multirow{2}{*}{$\begin{array}{c}\text { Space } \\
\text { lacking }\end{array}$} & \multicolumn{2}{|c|}{ Total } & \multicolumn{2}{|c|}{ Males } & \multicolumn{2}{c|}{ Females } & \multicolumn{2}{c|}{ Genders difference } \\
\cline { 2 - 10 } & No. & $\%$ & No. & $\%$ & No. & $\%$ & Z-test & p-value \\
\hline Right side & 98 & 47.80 & 51 & 42.15 & 47 & 55.95 & -1.946 & 0.051 (NS) \\
\hline Left side & 57 & 27.80 & 30 & 24.79 & 27 & 32.14 & -1.155 & $0.246(\mathrm{NS})$ \\
\hline Both sides & 50 & 24.39 & 40 & 33.06 & 10 & 11.90 & 3.468 & $0.000(\mathrm{HS})$ \\
\hline Total & 205 & 100 & 121 & 100 & 84 & 100 & & \\
\hline
\end{tabular}

$X^{2}=12.035$, d.f. $=2$, p-value $=0.002(H S)$

\section{DISCUSSION}

Prevalence of buccally malposed canines in Sammawa city

The prevalence of buccally malposed maxillary canine in this study was $9.72 \%$, this was higher than Ghaib $^{(11)}(8.36 \%)$, Al-Huwaizi ${ }^{(14)}$ (6.5\%), Al-Chalabi (22) $(4.6 \%)$, and lower than Al-Fahdawi ${ }^{(16)}(42.35 \%)$ and Aziz ${ }^{(18)}(10.8 \%)$; this is due to the difference in sample size and selection.

This problem affected males more than females due to the smaller dental arch of females.

\section{Prevalence of buccally malposed canines on sides of the maxillary arch}

High frequency of buccally malposed canines was reported at one side and in the right side more than the left with a non-significant gender difference. Ghaib (11) reported high prevalence of unilateral buccally malposed canines.

Al-Fahdawi (16) and Al-Chalabi (22) found high frequency of buccally malposed canines on the right side in reverse to Al-Huwaizi ${ }^{(14)}$ and Aziz ${ }^{(18)}$.

Buccally malposed canines in relation to the sagittal occlusal relationship

High frequency of buccally malposed maxillary canines was found in class I sagittal occlusion more than other classes; because the dominance type of occlusion is class I, so it is reasonable to find a higher percentage of canine problems in class I sagittal occlusion.

Bass (27) reported lower percentage of Class II cases affected with displaced canines as greater amount of space will be available in such cases due to proclined incisors that reduced the opportunity of an early canine deflection whether buccally or palatally and gave this tooth a high chance to carry on its correct path of eruption.

All classes showed non-significant gender difference. This comes in agreement with Ghaib ${ }^{(11)}$, Al-Fahdawi ${ }^{(16)}$ and Aziz ${ }^{(18)}$.

\section{Angulation of buccally malposed canines}

High frequency of mesially angulated buccally malposed canines than distally angulated one had been reported in this study in addition no significant gender difference between prevalence of mesially and distally angulated buccally malposed canines. This is due to its eruption path and this gives a real fact that the causative factors for the canine problems in males and females are similar mostly due to local factors in other word the canine problems outside the hormonal effect. These results are supported by Kinaan ${ }^{(9)}$, Farah ${ }^{(10)}$, Ghaib ${ }^{(11)}$, Al-Fahdawi ${ }^{(16)}$ and Aziz ${ }^{(19)}$.

\section{Buccally malposed canine and crowding}

High frequency of buccally malposed canine associated with crowding was showed in this study with no significant gender difference. This may be due to lack of space and small arch.

\section{Buccally malposed canine and retard deciduous canine}

Non-significant gender difference for the prevalence of buccally malposed canine associated with retard deciduous canine was shown in this study. Retard deciduous canine cannot be considered as a causative factor for the buccally malposed canine since there is no tendency of matching the occurrence of cases of retard deciduous canine on the maxillary arch in the cases of buccally malposed canine (Chi 
square revealed non-significant association). Early loss of deciduous canine may affect the permanent canine, whereas late loss (over 14 years old) of the deciduous canine may not have the same effect on the permanent canine.

\section{Buccally malposed canine and space lacking}

Highly significant association was found between prevalence of buccally malposed canine and space lacking. Buccally malposed canine has a significant tendency to be existed on the same side of the space lacking on the maxillary arch. Insufficient room in the dental arch and a vertical developmental position are often associated with buccal canine malposition ${ }^{(28)}$. This finding agrees with Al-Fahdawi ${ }^{(16)}$.

\section{CONCLUSIONS}

Regular visits of the children to the general practitioners and /or orthodontists are mandatory trying to preserve the deciduous teeth and to educate the parents about the importance of these teeth. In addition to that, the age between 9 to 10 years is important to detect the bulging of canines trying to minimize the possibility of ectopic canine eruption.

\section{REFERENCES}

1. Kraus BS. Dental anatomy and occlusion. 1st ed. Baltimore: Lippincott Williams \& Wilkins; 1969.

2. Ash MM, Ramfjord SP. Occlusion. 4th ed. Philadelphia: W.B. Saunders Co.; 1995.

3. Nelson SJ, Ash MM, Jr. Wheeler's dental anatomy, physiology and occlusion. 10th ed. St. Louis: Saunders An imprint of Elsevier Inc.; 2015.

4. Ismail AMA, Al-Nimi KDS. No more extraction of impacted upper canines in Iraqi patients. Iraqi Dent J 1989; 14:16373.

5. Dewel B. The upper cuspid: Its development and impaction. Angle Orthod 1949; 19(2): 79-90.

6. Ngan P, Hornbrook R, Weaver B. Early timely management of ectopically erupting maxillary canines. Semin Orthod 2005; 11(3): 152-63.

7. Sachan A, Chaturvedi TP. Orthodontic management of buccally erupted ectopic canine with two case reports. Contemporary Clin Dentistry 2012; 3(1): 123-8.

8. Kinaan BK. The problem of malocclusion in Iraq. Iraqi Dent J 1982; 9: 24-8.

9. Kinaan BK. Management of buccally malposed upper canine. Iraqi Dent J 1983; 10: 15-23.

10. Farah ME. The orthodontic examination of children aged 9 and 10 years from Baghdad, Iraq - A clinical and radiographic study. A master thesis, Department of POP, College of Dentistry, University of Baghdad, 1988.

11. Ghaib NH. Buccally malposed maxillary canines a survey of school children aged 13-14 years. A master thesis, Department of POP, College of Dentistry, University of Baghdad, 1992.

12. Al-Yassine KN. An Orthopantamographic study of prevalence, angulation and positional variations of impacted maxillary canines. A master thesis, Department of POP, College of Dentistry, University of Baghdad, 1995.

13. Abdulla NM. Occlusal features and perception: a sample of 13-17 years old adolescent. A master thesis, Department of POP, College of Dentistry, University of Baghdad, 1996.

14. Al-Huwaizi AFH. Occlusal features, perception of occlusion, orthodontic treatment, need and demand among 13 year Iraqi students. Ph.D. Thesis, Department of POP, College of Dentistry, University of Baghdad, 2002.

15. Al-Yassine KN. Prevalence and angulation of impacted mandibular canine: A clinical and radiological study. Iraqi Dent J 2003; 33: 323-32.

16. Al-Fahdawi DD. Maxillary canine problems in adolescent students from Ramadi City. A master thesis, Department of Orthodontics, College of Dentistry, University of Baghdad, 2005.

17. Saloom HF. The early detection of maxillary canine eruptive anomaly (orthopantomographic study). Iraqi Orthod J 2006; 2(1): 20-3.

18. Aziz BM. Prevalence of permanent maxillary malposed canine in a sample of students of secondary schools in Erbil city. A master thesis, College of Dentistry, Hawler Medical University, 2008.

19. Aziz ZH. Problems related to permanent maxillary canine in skeletal class I jaw relationship in Sulaimani Kurd students aged 18-22 Years. A master thesis, College of Dentistry, Sulaimani University, 2008.

20. Al-Ani AA. Evaluation of upper canine eruptive course: a radiographic study. Mustansiria Dent J 2010; 7(2): 191-7.

21. Al-Dabagh DJ. Buccally malposed mandibular canine in Iraqi Kurdish population. Iraqi Orthod J 2011; 7(1): 8-11.

22. Al-Chalabi ZMR. Occlusal features, perception of occlusion and orthodontic treatment need and demand among 13 years aged Baghdadi students (A comparative cross sectional epidemiological study). A master thesis, Department of Orthodontics, College of Dentistry, University of Baghdad, 2014.

23. World Health Organization. Oral health surveys: Basic methods. 4th ed. Geneva: WHO The Organization; 1997.

24. Baume LJ, Horowitz HS, Summers CJ, Backer Dirks O, Carlos JP, Cohen LK, et al. A method for measuring occlusal traits developed by the FDI commission on classification and statistics for oral conditions. Int Dent J 1973; 23(3): 530-7.

25. Björk A, Krebs A, Solow B. A method for epidemiological registration of malocclusion. Acta Odontol Scand 1964; 22(1): 27-41.

26. Angle EH. Classification of malocclusion. Dent Cosmos 1899; 41(2): 248-64.

27. Bass TB. Observations on the misplaced upper canine tooth. Dent Practit Dent Rec 1967; 18(1): 25-33.

28. Rayne J. The unerupted maxillary canine. Dent Practit Dent Rec 1969; 19(6):194-204. 